\title{
ANALISIS KETERLAMBATAN WAKTU PADA PROYEK PEMBANGUNAN RUMAH SUSUN KEJAKSAAN TINGGI PROVINSI KALIMANTAN TENGAH
}

\author{
Refki Maulana \\ Jurusan/Program Studi Teknik Sipil, Fakultas Teknik, Universitas Palangka Raya \\ Jln. Hendrik Timang, Palangka Raya, e-mail: refkimaulana95@yahoo.com \\ Apria Brita Pandohop Gawei \\ Jurusan/Program Studi Teknik Sipil, Fakultas Teknik, Universitas Palangka Raya \\ Jln. Hendrik Timang, Palangka Raya, e-mail: apria_gawei@yahoo.com \\ Veronika Happy Puspasari \\ Jurusan/Program Studi Teknik Sipil, Fakultas Teknik, Universitas Palangka Raya \\ Jln. Hendrik Timang, Palangka Raya, e-mail: vhappy_75@yahoo.com
}

\begin{abstract}
Construction of Flats for the High Prosecutor's Office in Central Kalimantan Province, according to data the time reporting implementation construction project, poyek experienced delays in implementation time. To know the duration time delay required a time performance analysis. study conducted a time performance analysis and analysis of the duration delay in project completion, which is expected to be useful initial action controlling time and improve project time performance again. The data analysis method used is a Earned Duration method (ED). In the Earned Duration method, Actual Duration (AD), Total Planned Duration (TPD) and Total Earned Duration (TED) indicator is used, and the final result of Total Duration Variance (TDV) which can find the late duration project. The data collection process is carried owner, project consultants and contractors well direct identification of project implementation locations. Analysis of time performance and time delay analysis using the Earned Duration (ED) method at the time of the 16th week of reporting the 4th month obtained the estimated reporting time of Earned Duration at Time (EDt) 95 days. Explained that time Earned Duration at Time (EDt) which can be less than 112 days of reporting time. Project time performance results Duration Performance Index (DPI) $(0,8482)<1$, From the results of time performance shows time performance project has decreased implementation. From the results of time performance analysis duration project can be carried Total Duration Variance (TDV) 17 days.
\end{abstract}

Keyword: time performance, time delay, development project, earned duration

\begin{abstract}
Abstrak: Pembangunan Rumah Susun Kejaksaan Tinggi Provinsi Kalimantan Tengah, menurut data waktu pelaporan pelaksanaan proyek pembangunan rumah susun, poyek mengalami keterlambatan waktu pelaksanaan. Untuk mengetahui durasi keterlambatan waktu diperlukan analisis Kinerja waktu. Maka dalam penelitian ini melakukan analisis kinerja waktu dan analisis durasi keterlambatan waktu penyelesaian proyek, yang diharapkan dapat bermanfaat sebagai tindakan awal dalam melakukan pengendalian waktu serta dapat meningkatkan kembali kinerja waktu proyek. Metode analisis data yang digunakan adalah metode Earned Duration (ED). Dalam metode Earned Duration menggunakan indikator Actual Duration (AD), Total Planned Duration (TPD) dan Total Earned Duration (TED) dan mendapatkan hasil akhir Total Duration Variance $(T D V)$ yang dapat mengetahui durasi terlambat waktu proyek. Proses pengumpulan data dilakukan terhadap pemilik, konsultan dan kontraktor proyek serta identifikasi langsung di lokasi pelaksanaan proyek. Analisis kinerja waktu dan analisis waktu keterlambatan menggunakan metode Earned Duration (ED) pada waktu laporan minggu ke-16 bulan ke-4 memperoleh perkiraaan waktu pelaporan Earned Duration at Time (EDt) 95 hari. dapat dijelaskan bahwa waktu Earned Duration at Time (EDt) yang di dapat kurang dari 112 hari waktu pelaporan. Hasil kinerja waktu proyek Duration Performance Index $(D P I)(0,8482)<1$, dari hasil kinerja waktu menunjukan bahwa kinerja waktu proyek mengalami penurunan dalam pelaksanaan. Dari hasil kinerja waktu dapat di lakukan analisis durasi waktu keterlamabatan proyek Total Duration Variance (TDV) 17 hari.
\end{abstract}

Kata Kunci: kinerja waktu, keterlambatan waktu, proyek pembangunan, earned duration 


\section{PENDAHULUAN}

Manajemen proyek adalah usaha dalam suatu kegiatan agar kegiatan tersebut dapat tercapai secara efisien dan efektif (Imam, 1999). Manajemen proyek meliputi proses perencanaan kegiatan, pengaturan, pelaksanaan dan pengendalian. Tujuan dari proses manajemen adalah untuk mengusahakan agar semua rangkaian kegiatan tersebut dapat berjalan sesuai rencana (Imam, 1999). Pengendalian waktu dapat dilakukan dengan melihat kinerja pelaksanaan proyek yang telah berlangsung. Pelaksanaan suatu proyek dapat mengalami keterlambatan, percepatan, ataupun tepat waktu sesuai dengan jadwalan rencana proyek (Vendie, 2016). Metode earned duration adalah pengukuran, perkiraan atau prediksi durasi waktu penyelesaian proyek dengan memisahkan antara jadwal dan biaya pekerjaan. metode Earned Duration (ED) perkembangan dari metode Earned Value (EV) (Khamooshi, 2014). Earne Duration (ED) suatu metode baru yang dikembangkan dengan pendekatan dalam mengukur durasi pekerjaan sebuah proyek yang menggunakan indikator mirip dengan Earned Value (EV) namun menghilangkan penggunaan data biaya yang hanya menggunakan data waktu dalam memperkirakan penyelesaian sebuah proyek (Khamooshi, 2014). Basuki dkk (2017), melakukan penelitian model validasi penerapan hasil pengembangan Earned Value method untuk memperkirakan durasi akhir sebuah proyek konstruksi, dan dikatakan memprediksi durasi akhir proyek dapat dihitung lebih baik dengan menggunakan metode Earned Duration karena menghasilkan indeks kinerja Duration Performance Index (DPI) lebih akurat dibandingkan Schedule Performance Indek (SPI) yang terdapat pada metode Earned Value.

Salah satu keterlabatan waktu yang terjadi pada Pembangunan Rumah Susun Di Wilayah kota Palangka Raya yang memiliki waktu perencanaan proyek selama 180 hari masa kalender. Berdasarkan informasi pihak terkait dan data laporan mingguan pelaksanaan proyek pembangunan rumah susun mengalami keterlambatan waktu. Untuk mengetahui durasi waktu keterlambatan perlu dilakukan anasisis kinerja waktu dan analisis durasi waktu keterlabatan pelaksanaan maka dalam proses analisis kinerja waktu dan mengetahui durasi waktu keterlambatan proyek menggunakan perhitungan metrik sebagai pengolahan data awal yang nantinya digunakan sebagai indikator Earned Duration dan kita ketahui saat pelaporan di 112 hari kalender tepatnya pada minggu ke-16 bulan ke-4 Total Planned Daily addendum I 70,00 hari, Total Planned Cumulative addendum I 448,00 hari, Total Earned Daily addendum I 58,67, dan Total Earned Cumulative 413,00 diperkirakan kinerja proyek tidak mencapai waktu yang diinginkan maka waktu penyelesaian proyek diperkirakan terlambat. Oleh karena itu perlu dilakukan analisis kinerja waktu proyek dan keterlabatan waktu proyek tersebut agar keterlambatan yang terjadi dapat dikendalikan. Analisis kinerja waktu proyek dan waktu keterlambatan menggunakan metode Earned Duration. Metode Earned Duration adalah metode yang baru dikembangkan untuk pemantauan waktu proyek (Khamooshi, 2014). Metode Earned Duration dapat memberikan hasil perbedaan waktu atau sama dengan antara waktu pelaksanaan (Khamooshi, 2014). Analisis keterlambatan waktu pelaksanaan dilakukan pada minggu ke-16 bulan ke-4, yang bertujuan mengetahui kinerja proyek dan durasi waktu keterlambatan proyek, yang dapat bermanfaat sebagai modal awal melakukan pengendalian waktu dan meningkatkan kinerja proyek.

\section{TINJAUAN PUSTAKA}

\section{Kinerja Proyek}

Kinerja proyek dapat diukur dari kinerja biaya, mutu, waktu, serta keselamatan kerja dengan merencanakan secara cermat, teliti dan terpadu seluruh alokasi sumber daya, peralatan, material serta biaya yang sesuai dengan kebutuhan yang diperlukan. Manajemen proyek yang sangat mempengaruhi hasil akhir proyek adalah pengendalian yang mempunyai tujuan utama meminimalisir segala penyimpangan yang dapat terjadi selama proses berlangsungnya proyek (Pratama dkk, 2019).

\section{Waktu Proyek}

Waktu adalah lamanya durasi suatu kegiatan yang diukur dengan satuan jam, hari, minggu, bulan, dan tahun, yang menentukan berapa lama suatu proyek akan diselesaikan. Waktu normal adalah waktu yang diperlukan untuk melakukan kegiatan awal hingga selesainya sebuah pelaksanaan proyek dengan cara yang efisien, yang kanan dilakukan diluar pertimbangan seperti adanya sebuah kerja 
lembur, penambahan tenaga tukang dan usahausaha khusus lainnya (Rian, 2014). Proyek adalah suatu rangkaian beberapa kegiatan atau aktivitas dengan batas waktu yang telah direncanakan dan mengelola sumber daya yang digunakan dengan suatu metode tertentu dalam menggapai suatu tujuan (Olivia dkk, 2019).

\section{Konsep Earned Duration}

Earned Duration (ED) diperkenalkan oleh Khamooshi (2014), yang berfungsi untuk mengukur atau memprediksi durasi proyek dengan memisahkan antara jadwal dan biaya. Earned Duration (ED) diperkenalkan untuk menutupi kekurangan dari metode Panned Value Method (PVM) dan Earned Schedule Method (ESM) yang dapat memainkan peran yang sama seperti yang dilakukan Earned Value Method $(E V M)$ terhadap biaya. Earned Duration (ED) sebagai motode untuk memprediksi durasi penyelesaian proyek yang dapat membandingkan waktu rencana yang telah ditentukan. Berikut adalah gambaran Basic Earned Duration.

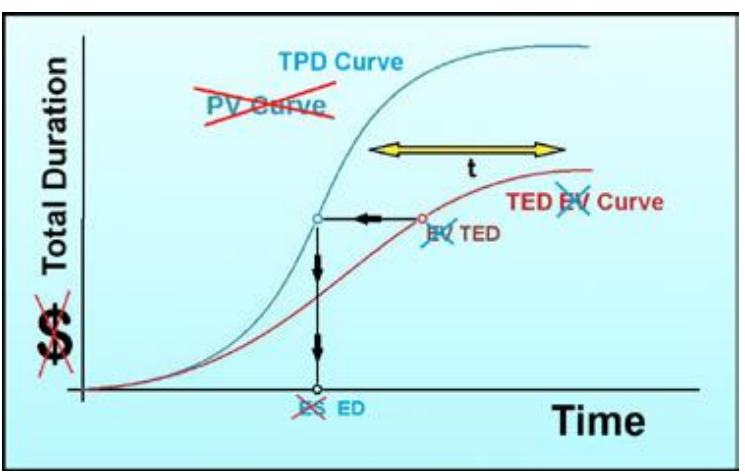

Gambar 1. Basic Earned Duration

Sumber : Khamooshi Golafshani (2014)

Earned Duration konsep menghitung panjangnya durasi waktu menurut waktu perencanaan yang sesuai dengan pelaksanaan pekerjaan yang telah diselesaikan. Bila ditinjau dari jumlah pekerjaan yang telah diselesaikan maka berarti konsep ini mengukur besarnya waktu pekerjaan yang telah diselesaikan dalam waktu tertentu (Khamooshi, 2014).

\section{Indikator Earned Duratioan Management (EDM)}

Dari gambaran basic Earned Duration diatas dapat dijelaskan sebagai berikut :

\section{AD (Actual Duration)}

AD adalah total waktu pekerjaan yang telah dilaksanakan dalam kurun waktu pelaporan. Dalam data ini dapat diperoleh dari waktu laporan harian, mingguan, bulanan atau waktu pekerjaan yang telah dilalui (Khamooshi, 2014).

\section{TPD (Total Planned Duration)}

TPD adalah total rencana waktu dalam periode pekerjaan yang telah disusun dengan jadwal pelaksanaan dalam perhitungan Total Planned Duration (TPD) tidak ada perpaduan antara biaya, namun hanya berkaitan dengan waktu jadwal dan lingkup pekerjaan, dimana setiap elemen pekerjaan telah diberikan alokasi jadwal yang dapat menjadi tolak ukur waktu pelaporan pelaksanaan pekerjaan (Khamooshi, 2014). Rumus TPD, adalah :

$$
\begin{aligned}
\text { TPD }(\text { daily }) \quad & \text { planned } \text { aktivitas ke- } 1+ \\
& \text { aktivitas selanjunya }
\end{aligned}
$$

$$
\begin{aligned}
& \text { TPD }(\text { cumulative })=\text { TED }(\text { cumulative }) \\
& \text { minggu sebelumnya }+ \\
& \text { TPD (daily) }
\end{aligned}
$$

\section{TED (Total Earned Duration)}

TED adalah total waktu yang diterima dari penyelesaian pekerjaan selama periode waktu tertentu. Total Earned Duration (TED) ini dihitung berdasarkan akumulasi dan konversi dari Earned Duration (ED). data ED didapat bedasarkan pekerjaan yang telah diselesaikan. Dengan menggunakan perhitungan ini dapat memperkirakan berapa lama waktu pelaksanaan proyek telah dilalui, berikut rumus perhitungan ED. (Khamooshi, 2014).

Rumus ED, adalah :

$\mathrm{ED}=\mathrm{PD} / \mathrm{AD}$

Keterangan :

$\begin{array}{ll}\mathrm{PD} & \text { : rencana waktu pekerjaan } \\ \mathrm{AD} & \text { : waktu yang dicapai }\end{array}$

Setelah perhitungan ED dapat dilanjutkan dengan perhitungan akumulasi TED, berikut rumus perhitungan akumulasi TED.

Rumus TED, adalah : 


$$
\begin{aligned}
& \text { TED (daily) = earned aktivitas Ke-1 + } \\
& \text { aktivitas selanjutnya. } \\
& \text { TED }(\text { cumulative })=\underset{\text { sebelumnya }}{\text { (daily ratio })}+\begin{array}{r}
\text { minggu } \\
\text { total }
\end{array}
\end{aligned}
$$

\section{4. (EDt) Earned Duration at Time}

EDt adalah waktu berdasarkan pekerjaan yang terlaksana selama periode waktu tertentu dan dibagi dengan waktu perencanaan (Khamooshi, 2014). Perhitungan EDt dapat mengukur lamanya waktu pelaksanaan. Rumus EDt, adalah :

$$
\mathrm{ED}_{\mathrm{t}}=\mathrm{t}+\frac{\mathrm{TED}-\mathrm{TPDt}}{(\mathrm{TPD} t+1)-\mathrm{TPDt}} \times 1(\mathrm{UC})
$$

Keterangan :

$$
\begin{array}{ll}
\mathrm{t} & : \text { waktu sekarang } \\
\mathrm{TED} & : \text { total durasi yang diperoleh } \\
\text { TPD } & : \text { total durasi rencana }
\end{array}
$$

\section{5. (DPI) Duration Performance Index}

DPI adalah faktor efesien kinerja waktu dalam menyelesaikan pekerjaan dapat diperlihatkan dengan perbandingan antara nilai pekerjaan secara fisik yang telah diselesaikan dengan rencana pengunaan waktu yang terpakai berdasarkan rencana pekerjaan (Khamooshi, 2014). Rumus DPI, adalah :

$\mathrm{DPI}=\mathrm{EDt} / \mathrm{AD}$

Keterangan :

DPI $>1$ : penyelesaian proyek lebih cepat

DPI $<1$ : penyelesaian proyek terlambat

$\mathrm{DPI}=1$ : penyelesaian proyek tepat waktu

AD : actual duration

6. (TDV) Total Duration Variance

TDV adalah perkiraan waktu waktu keterlambatan proyek yang berdasarkan perhitungan antara t dan EDt (Khamooshi, 2014). Rumus untuk TDV, adalah :

$\mathrm{TDV}=\mathrm{t}-\mathrm{ED}_{\mathrm{t}}$

\section{METODE PENELITIAN}

\section{Waktu Dan Tempat Penelitian}

Penelitian dan pengambilan data dilakukan pada Proyek Pembangunan Rumah Susun peruntukan Kejaksaan Tinggi Povinsi Kalimantan Tengah, Jalan Kapten Piere Tendean Kota Palangka Raya. Penelitian ini dimulai pada
14 Agustus 2018, pengamatan dan pengumpulan data dimulai pada 19 Agustus 2018 sampai dengan 29 September 2018.

\section{Tahapan Penelitian}

Tahap penelitian dilakukan dalam lima tahap, dimana tiap tahapan penelitian saling mempengaruhi satu sama lain, tahap kegiatan penelitian dijelaskan sebagai berikut :

1. Tahap pendahuluan penelitian meliputi penyusunan latar belakang, rumusan masalah, batasan masalah, tujuan penelitian, manfaat penelitian.

2. Tahap landasan teori penelitian mencakup literatur-literatur yang berkaitan dengan penelitian.

3. Tahap pengumpulan data penelitian meliputi observasi ke lokasi pelaksaan proyek pembangunan, melihat secara langsung proses pekerjaan yang dilakukan.

4. Tahap hasil penelitian dan pembahasan, pada tahapan ini mencakup pengolahan data dengan mengetahui penyimpangan waktu penyelesaian proyek.

5. Tahap penutup, tahapan ini adalah penarikan kesimpulan dari proses analisis data dan memberikan saran terhadap hasil penelitian.

\section{Metode Pengumpulan Data}

Metode yang digunakan dalam penelitian ini adalah metode analisis deskriptif, yaitu metode untuk memecahkan suatu masalah yang ada dengan cara mengumpulkan data, dan pengamatan langsung dilapangan dengan tahapan sebagai berikut :

1. Data Primer

Data primer merupakan data pengamatan langsung dilapangan dengan, wawancara pada pihak terkait dilapangan.

2. Data Sekunder

Data sekunder dalam penelitian ini yaitu :

a. Laporan harian, mingguan dan bulanan pekerjaan.

b. Time schedule pelaksanaan atau kurva S.

\section{Teknik Analisis Data}

1. Perhitungan total rencana waktu dalam periode pekerjaan yang telah disusun dengan jadwal pelaksanaan dengan persamaan (1) dan (2).

2. Perhitungan waktu yang diterima dari penyelesaian pekerjaan selama periode 
pelaporan minggguan dengan pesamaan (3), (4) dan (5).

3. Perhitungan total waktu yang diterima selama pelaporan yang dibuat dalam bentuk tabel metrik Total Actual Duration (TAD), Total Planned Duration (TPD), dan Total Earned Duration (TED) dapat dilihat pada tabel 1 dan rekap perhitungan pada tabel 2 .

4. Perhitungan waktu berdasarkan pekerjaan yang terlaksana selama periode waktu pelaporan dan dibagi dengan waktu perencanaan dengan persamaan (6)

5. Perhitungan faktor efesien kinerja waktu proyek dalam menyelesaikan pekerjaan dapat diperlihatkan dengan perbandingan antara nilai pekerjaan secara fisik yang telah diselesaikan dengan persamaan (7)

6. Perhitungan perkiraan durasi waktu keterlambatan proyek yang berdasarkan perhitungan antara $\mathrm{t}$ dan EDt dengan persamaan (8)

\section{HASIL PENELITIAN DAN PEMBAHASAN}

\section{Pengolahan Data}

Data yang telah dikumpulkan dan akan diolah dalam bentuk perhitungan dan tabel metrik lalu dilanjutkan dengan analisis kinerja waktu serta perhitungan waktu keterlambatan yang terjadi pada Proyek Pembangunan Rumah Susun Kejaksaan Tinggi, maka dalam penelitian ini terdapat beberapa proses analisis data awal yang dilakukan seperti Total Planned Duration (TPD), dan analisis data jumlah Planned Duration (PD), jumlah Actual Duration (AD), yang diberi keterangan pada tabel Total Duration (TD), dan Daily Ratio (DR), sebagai indikator akumulasi Total Earned Duration (TED). Akumulasi Total Earned Duration melalui tahap perhitungan dalam bentuk metrik yaitu, berikut contoh analisis data awal TPD dan analisis data TED melalui indikator PD, AD dan ED (ratio).

\section{Total Planned Duration (TPD)}

TPD mengetahui total rencana waktu pada tiap aktivitas pekerjaan. Contoh perhitungan TPD dilakukan pada minggu ke-16, berikut cara perhitungan TPD.

Perhitungan untuk TPD, adalah :

Perhitungan pada minggu ke-16

$$
\begin{aligned}
\operatorname{TPD} \text { (daily) } & =\text { planned } \text { aktivitas ke- } 1+ \\
& \text { aktivitas selanjunya } \\
\operatorname{TPD} \text { (daily) } & 7,00+7,00+7,00+7,00 \\
& +7,00+7,00+7,00+7,00 \\
& +7,00+7,00 \\
= & 70,00 \text { hari }
\end{aligned}
$$

TPD $($ cumulative $)=$ TED $($ cumulative $)$ minggu sebelumnya + TPD (daily)

TPD $($ cumulative $)=378,00+70,00$

$$
=448,00 \text { hari }
$$

\section{Total Earned Duration (TED)}

Perhitungan TED mencari total waktu yang diterima dari tiap penyelesaian pekerjaan dengan cara konversi ED (ratio). Berikut contoh perhitungan konversi ED (ratio) pada aktivitas ke-2 dan akumulasi TED pada minggu ke-16.

Perhitungan unruk ED, adalah :

Perhitungan aktivitas ke-2

$$
\begin{array}{ll}
\mathrm{ED} & =\mathrm{PD} / \mathrm{AD} \\
\mathrm{PD} & =7 \text { minggu }=49,00 \text { hari } \\
\mathrm{AD} & =11 \text { minggu } \\
\mathrm{ED}(\text { ratio }) & =(49,00 / 11)=4,45 \text { hari }
\end{array}
$$

Tabel 1. Rekap data PD dan AD aktivitas ke-2

\begin{tabular}{|c|c|c|}
\hline $\begin{array}{c}\text { Minggu } \\
\text { Ke- }\end{array}$ & $\begin{array}{c}\text { PD } \\
\text { Hari }\end{array}$ & $\begin{array}{c}\text { AD } \\
\text { Hari }\end{array}$ \\
\hline 6 & & 7,00 \\
\hline 7 & 7,00 & 7,00 \\
\hline 8 & 7,00 & 7,00 \\
\hline 9 & 7,00 & 7,00 \\
\hline 10 & 7,00 & 7,00 \\
\hline 11 & 7,00 & 7,00 \\
\hline 12 & 7,00 & 7,00 \\
\hline 13 & 7,00 & 7,00 \\
\hline 14 & & 7,00 \\
\hline 15 & & 7,00 \\
\hline 16 & & 7,00 \\
\hline Total & 49,00 & 77,00 \\
Duration & & \\
\hline
\end{tabular}

Sumber : Pengolahan Data

Hasil dari ED (ratio) pada aktivitas ke-2 mendapatkan 4,45 hari. Maka dapat kita perjelas dari hasil ED (ratio) 4,45 hari pada aktivitas ke2 tidak mencapai rencana pekerjaan dalam 1 minggu. Hasil dari perhitungan ED (daily ratio) pada aktivitas ke-2 pada tiap waktu pelaporan 7 hari sekali hanya mencapai 4,45 hari. untuk memperjelas durasi rencana dan waktu yang 
telah diterima dalam kurun waktu pelaporan dapat dilihat pada tabel 2. Berikut tabel rekap data $\mathrm{PD}$ dan $\mathrm{AD}$ aktivitas ke-2 berdasarkan waktu pelaporan. Setelah hasil perhitungan konversi ED (daily ratio) tiap pelaporan 7 hari sekali didapat maka dapat dilanjutkan dengan perhitungan akumulasi TED. Contoh perhitungan akumulasi TED kita lakukan pada minggu ke-16, berikut tahap perhitungan akumulasi TED.

Perhitungan akumulasi TED, adalah :

Perhitungan pada minggu ke-16

TED (daily) = $\begin{aligned} & \text { earned atifitas ke- } 1+ \\ & \text { aktivitas selanjutnya }\end{aligned}$
TED (daily) $\quad=7,00+4,45+3,50+4,67+$ $1,40+4,20+3,50+5,44$ $+7,00+14,00=58,67$

TED $($ cumulative $)=$ TED $($ cumulative $)$ minggu sebelumnya + TED (daily)

TED $($ cumulative $)=354,33+58,67$

$$
=413,00 \text { hari }
$$

Hasil perhitung an TPD minggu ke-16, TPD (cumulative) 448,00 hari dan hasil perhitungan TED minggu ke-16, TED (cumulative) 413,00 hari. Untuk memperjelas hasil dari perhitungan diatas dapat dilihat pada tabel 2. Sebagai berikut contoh perhitungan matrik yang diltampilkan tiap akhir bulan pelaporan.

Tabel 2. Metrik total earned duration

\begin{tabular}{|c|c|c|c|c|c|c|c|c|c|c|c|c|c|c|c|c|c|c|c|}
\hline \multirow{2}{*}{ AK } & & M & $\mathbf{M}$ & $\mathbf{M}$ & M & M & M & $\mathbf{M}$ & M & $\mathbf{M}$ & M & $\mathbf{M}$ & $\bar{M}$ & $\bar{M}$ & $\bar{M}$ & $\bar{M}$ & $\mathbf{M}$ & TD & $\overline{D R}$ \\
\hline & & 1 & 2 & 3 & 4 & 5 & 6 & 7 & 8 & 9 & 10 & 11 & 12 & 13 & 14 & 15 & 16 & Hari & Hari \\
\hline \multirow{3}{*}{1} & $\mathrm{P}$ & 7,00 & 7,00 & 7,00 & 7,00 & 7,00 & 7,00 & 7,00 & 7,00 & 7,00 & 7,00 & 7,00 & 7,00 & 7,00 & 7,00 & 7,00 & 7,00 & 112,00 & \\
\hline & A & 7,00 & 7,00 & 7,00 & 7,00 & 7,00 & 7,00 & 7,00 & 7,00 & 7,00 & 7,00 & 7,00 & 7,00 & 7,00 & 7,00 & 7,00 & 7,00 & 112,00 & \\
\hline & $\mathrm{E}$ & 14,00 & 14,00 & 7,00 & 7,00 & 7,00 & 7,00 & 7,00 & 7,00 & 7,00 & 7,00 & 7,00 & 7,00 & 7,00 & 7,00 & 7,00 & 7,00 & & 7,00 \\
\hline \multirow{3}{*}{2} & $P$ & & & & & & & 7,00 & 7,00 & 7,00 & 7,00 & 7,00 & 7,00 & 7,00 & & & & 49,00 & \\
\hline & A & & & & & & 7,00 & 7,00 & 7,00 & 7,00 & 7,00 & 7,00 & 7,00 & 7,00 & 7,00 & 7,00 & 7,00 & 77,00 & \\
\hline & $\mathrm{E}$ & & & & & & 4,45 & 4,45 & 4,45 & 4,45 & 4,45 & 4,45 & 4,45 & 4,45 & 4,45 & 4,45 & 4,45 & & 4,45 \\
\hline \multirow{3}{*}{3} & $\mathrm{P}$ & & & & & & & & & & & & & & 7,00 & 7,00 & 7,00 & 21,00 & \\
\hline & A & & & & & & & & & & & 7,00 & 7,00 & 7,00 & 7,00 & 7,00 & 7,00 & 42,00 & \\
\hline & $E$ & & & & & & & & & & & 3,50 & 3,50 & 3,50 & 3,50 & 3,50 & 3,50 & & 3,50 \\
\hline \multirow{3}{*}{4} & $\mathrm{P}$ & & & & & & & & & & & & & & & & 7,00 & 7,00 & \\
\hline & A & & & & & & & & & & & & & & & 7,00 & 7,00 & 14,00 & \\
\hline & $\mathrm{E}$ & & & & & & & & & & & & & & & 3,50 & 3,50 & & 3,50 \\
\hline \multirow{3}{*}{5} & $P$ & & & & & & & & & & & & & 7,00 & 7,00 & 7,00 & 7,00 & 28,00 & \\
\hline & A & & & & & & & & & & & 7,00 & 7,00 & 7,00 & 7,00 & 7,00 & 7,00 & 42,00 & \\
\hline & $\mathrm{E}$ & & & & & & & & & & & 4,67 & 4,67 & 4,67 & 4,67 & 4,67 & 4,67 & & 4,67 \\
\hline \multirow{3}{*}{6} & $\mathrm{P}$ & & & & & & & & & & & & & & & & 7,00 & 7,00 & \\
\hline & A & & & & & & & & & & & & 7,00 & 7,00 & 7,00 & 7,00 & 7,00 & 35,00 & \\
\hline & $\bar{E}$ & & & & & & & & & & & & 1,40 & 1,40 & 1,40 & 1,40 & 1,40 & & $-\overline{1,40}$ \\
\hline \multirow{3}{*}{7} & $\stackrel{P}{P}$ & & & & & & & & & & & & & & 7,00 & 7,00 & 7,00 & 21,00 & \\
\hline & A & & & & & & & & & & & & 7,00 & 7,00 & 7,00 & 7,00 & 7,00 & 35,00 & \\
\hline & $\bar{E}$ & & & & & & & & & & & & 4,20 & 4,20 & 4,20 & 4,20 & 4,20 & & 4,00 \\
\hline \multirow{3}{*}{8} & $P$ & & & & & & & & & & & & & & & 7,00 & 7,00 & 14,00 & \\
\hline & A & & & & & & & & & & & & & & & & & & \\
\hline & $\bar{E}$ & & & & & & & & & & & & & & & & & & \\
\hline \multirow{3}{*}{9} & $\stackrel{P}{P}$ & & & & & & & & & & & & & & & 7,00 & 7,00 & 14,00 & \\
\hline & A & & & & & & & & & & & & & 7,00 & 7,00 & 7,00 & 7,00 & 28,00 & \\
\hline & $\bar{E}$ & & & & & & & & & & & & & 3,50 & 3,50 & 3,50 & 3,50 & & 3,50 \\
\hline \multirow{3}{*}{10} & $P$ & & & 7,00 & 7,00 & 7,00 & 7,00 & 7,00 & 7,00 & & & & & & & & & 42,00 & \\
\hline & A & & & 7,00 & 7,00 & 7,00 & 7,00 & 7,00 & 7,00 & 7,00 & 7,00 & 7,00 & 7,00 & & & & & 70,00 & \\
\hline & $\mathrm{E}$ & & & 4,20 & 4,20 & 4,20 & 4,20 & 4,20 & 4,20 & 4,20 & 4,20 & 4,20 & 4,20 & & & & & & 4,20 \\
\hline \multirow{3}{*}{11} & $\mathrm{P}$ & & & & & 7,00 & 7,00 & 7,00 & 7,00 & 7,00 & 7,00 & 7,00 & & & & & & 49,00 & \\
\hline & A & & & & & & & & 7,00 & 7,00 & 7,00 & 7,00 & 7,00 & 7,00 & 7,00 & 7,00 & 7,00 & 63,00 & \\
\hline & $\mathrm{E}$ & & & & & & & & 5,44 & 5,44 & 5,44 & 5,44 & 5,44 & 5,44 & 5,44 & 5,44 & 5,44 & & 5,44 \\
\hline \multirow{3}{*}{12} & $P$ & & & & & & & & & & & & & 7,00 & 7,00 & 7,00 & & 21,00 & \\
\hline & A & & & & & & & & & & & & & & 7,00 & 7,00 & 7,00 & 21,00 & \\
\hline & $\bar{E}$ & & & & & & & & & & & & & & 7,00 & 7,00 & $\overline{7,00}$ & & $-\overline{7,00}$ \\
\hline \multirow{3}{*}{13} & $\underline{P}$ & & & & & & & & & & & & 7,00 & 7,00 & 7,00 & 7,00 & 7,00 & 35,00 & \\
\hline & A & & & & & & & & & & & & & & & & & & \\
\hline & $\mathrm{E}$ & & & & & & & & & & & & & & & & & & \\
\hline \multirow{3}{*}{14} & 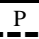 & & & & & & & & & & & & & 7,00 & 7,00 & 7,00 & 7,00 & 28,00 & 14 \\
\hline & A & & & & & & & & & & & & & & & 7,00 & 7,00 & 14,00 & \\
\hline & $\mathrm{E}$ & & & & & & & & & & & & & & & 14,00 & 14,00 & & \\
\hline
\end{tabular}


Tabel 2. Lanjutan

\begin{tabular}{|c|c|c|c|c|c|c|c|c|c|c|c|c|c|c|c|c|c|c|c|}
\hline \multirow{2}{*}{ AK } & & M & $\mathbf{M}$ & M & M & $\mathbf{M}$ & M & M & M & M & M & M & M & M & M & M & M & TD & DR \\
\hline & & 1 & 2 & 3 & 4 & 5 & 6 & 7 & 8 & 9 & 10 & 11 & 12 & 13 & 14 & 15 & 16 & Hari & Hari \\
\hline \multirow{2}{*}{$\mathrm{P}$} & D & 7,00 & 7,00 & 14,00 & 14,00 & 21,00 & 21,00 & 28,00 & 28,00 & \begin{tabular}{|l|}
21,00 \\
\end{tabular} & \begin{tabular}{|l|}
21,00 \\
\end{tabular} & \begin{tabular}{|l|}
21,00 \\
\end{tabular} & \begin{tabular}{|l|}
21,00 \\
\end{tabular} & \begin{tabular}{|l|}
42,00 \\
\end{tabular} & \begin{tabular}{|l|}
49,00 \\
\end{tabular} & \begin{tabular}{|l|}
63,00 \\
\end{tabular} & 70,00 & & \\
\hline & C & 7,00 & 14,00 & 28,00 & 42,00 & 63,00 & 84,00 & 112,00 & 140,00 & $\mid 161,00$ & 182,00 & 203,00 & 224,00 & 266,00 & 315,00 & 378,00 & 448,00 & & \\
\hline \multirow{2}{*}{$\mathrm{E}$} & D & 14,00 & 14,00 & 11,20 & 11,20 & 11,20 & 15,65 & \begin{tabular}{|l|}
15,65 \\
\end{tabular} & 21,10 & \begin{tabular}{|l|}
21,10 \\
\end{tabular} & \begin{tabular}{|l|}
21,10 \\
\end{tabular} & \begin{tabular}{|l|}
29,27 \\
\end{tabular} & \begin{tabular}{|l|}
34,87 \\
\end{tabular} & \begin{tabular}{|l|}
34,17 \\
\end{tabular} & 41,17 & \begin{tabular}{|l|}
58,67 \\
\end{tabular} & 58,67 & & \\
\hline & $\mathrm{C}$ & 14,00 & 28,00 & 39,20 & 50,40 & 61,60 & 77,25 & 92,91 & 114,01 & 135,11 & 156,21 & 185,47 & \begin{tabular}{|l|}
220,34 \\
\end{tabular} & 254,50 & 295,67 & 354,33 & 413,00 & & \\
\hline
\end{tabular}

Sumber: Pengolahan Data

Keterangan :

$\begin{array}{ll}\mathrm{AK} & =\text { Aktivitas } \\ \mathrm{M} & =\text { Minggu } \\ \mathrm{TD} & =\text { Total Durasi } \\ \mathrm{DR} & =\text { Durasi Ratio } \\ \mathrm{P} & =\text { Planned } \\ \mathrm{A} & =\text { Actual } \\ \mathrm{E} & =\text { Earned } \\ \mathrm{D} & =\text { Daily } \\ \mathrm{C} & =\text { Cumulatif }\end{array}$

Dari proses pengolahan data dalam bentuk tabel metrik Total Earned Duration diatas mendapatkan nilai sebagai indikator perhitungan Earned Duration at Time. Maka dari itu untuk memperjelas data indikator Earned Duration at Time dapat kita dilanjutkan dengan pembuatan Rekap Total Planned Duration (TPD) dan Total Earned Duration (TED) sebagai berikut :

Tabel 3. Hasil rekap perhitungan TPD dan TED

\begin{tabular}{|c|c|c|c|c|c|}
\hline $\begin{array}{c}\text { Minggu } \\
\text { Ke- }\end{array}$ & $\begin{array}{c}\mathbf{t} \\
\text { Hari }\end{array}$ & $\begin{array}{c}\text { PD } \\
\text { Hari }\end{array}$ & $\begin{array}{c}\text { TPD } \\
\text { Hari }\end{array}$ & $\begin{array}{c}\text { ED } \\
\text { Hari }\end{array}$ & $\begin{array}{c}\text { TED } \\
\text { Hari }\end{array}$ \\
\hline 1 & 7,00 & 7,00 & 7,00 & 14,00 & 14,00 \\
\hline 2 & 14,00 & 7,00 & 14,00 & 14,00 & 28,00 \\
\hline 3 & 21,00 & 14,00 & 28,00 & 11,20 & 39,20 \\
\hline 4 & 28,00 & 14,00 & 42,00 & 11,20 & 50,40 \\
\hline 5 & 35,00 & 21,00 & 63,00 & 11,20 & 61,60 \\
\hline 6 & 42,00 & 21,00 & 84,00 & 15,65 & 77,25 \\
\hline 7 & 49,00 & 28,00 & 112,00 & 15,65 & 92,91 \\
\hline 8 & 56,00 & 28,00 & 140,00 & 21,10 & 114,01 \\
\hline 9 & 63,00 & 21,00 & 161,00 & 21,10 & 135,11 \\
\hline 10 & 70,00 & 21,00 & 182,00 & 21,10 & 156,21 \\
\hline 11 & 77,00 & 21,00 & 203,00 & 29,27 & 185,47 \\
\hline 12 & 84,00 & 21,00 & 224,00 & 34,87 & 220,34 \\
\hline 13 & 91,00 & 42,00 & 266,00 & 34,17 & 254,50 \\
\hline 14 & 98,00 & 49,00 & 315,00 & 41,17 & 295,67 \\
\hline 15 & 105,00 & 63,00 & 378,00 & 58,67 & 354,33 \\
\hline 16 & 112,00 & 70,00 & 448,00 & 58,67 & 413,00 \\
\hline
\end{tabular}

Sumber : Pengolahan Data
Nilai t adalah waktu yang ditetapkan pada saat periode pelaporan, TPD adalah total waktu rencana pekerjaan yang dijumlah pada setiap periode pelaporan, dan TED adalah total waktu pekerjaan yang telah dilaksanakan dalam kurun waktu tertentu dan dijumlahkan pada setiap periode pelaporan. Perhitungan Earned Duration (ED) pada metrik aktivitas pekerjaan ke-2 mendapat waktu 4,45 hari. untuk mendapatkan waktu TED yaitu total dari perhitungan ED yang berada pada tiap uraian pekerjaan yang menghasilkan waktu 413,00 hari.

Dari Tabel 3 hasil rekap perhitungan TPD dan TED diatas dapat dilanjutkan dengan perhitungan Earned Duration at Time (EDt) diambil pada Pengolahan Data minggu ke-16 bulan ke-4 menggunakan perhitungan sebagai berikut.

\section{Earned Duration at Time (EDt)}

Perhitungan EDt dapat mengetahui durasi waktu yang diterima pada saat pelaporan.

Perhitungan untuk EDt, adalah :

$\mathrm{ED}_{\mathrm{t}}=\mathrm{t}+\frac{\mathrm{TED}-\mathrm{TPDt}}{(\mathrm{TPD} t+1)-\mathrm{TPD} t} \times 1(\mathrm{UC})$

Minggu Ke-16 Bulan Ke-4

$\mathrm{t}=112$ hari

$\mathrm{TPD}=448,00$ hari

TED $=413,00$ hari

$\mathrm{ED}_{\mathrm{t}}=112+\frac{(413,00-448,00)}{((448,00+(448,00 \times 2))-448,00)} \mathrm{X}$ 448,00

$=95,00$ hari

Keterangan :

t : waktu sekarang

TED : total durasi yang diperoleh

TPD : total durasi rencana

Untuk memperjelas hasil perhitungan tiap minggu dapat dilihat dalam bentuk tabel 4 . 
Berikut tabel 4. Rekap Earned Duration at Time (EDt).

Tabel 4. Rekap earned duration at time

\begin{tabular}{|c|c|c|c|c|}
\hline $\begin{array}{c}\text { Minggu } \\
\text { Ke- }\end{array}$ & $\begin{array}{c}\mathbf{t} \\
\text { Hari }\end{array}$ & $\begin{array}{c}\text { TPD } \\
\text { Hari }\end{array}$ & $\begin{array}{c}\text { TED } \\
\text { Hari }\end{array}$ & $\begin{array}{c}\text { EDt } \\
\text { Hari }\end{array}$ \\
\hline 1 & 7,00 & 7,00 & 14,00 & 11,00 \\
\hline 2 & 14,00 & 14,00 & 28,00 & 21,00 \\
\hline 3 & 21,00 & 28,00 & 39,20 & 27,00 \\
\hline 4 & 28,00 & 42,00 & 50,40 & 33,00 \\
\hline 5 & 35,00 & 63,00 & 61,60 & 35,00 \\
\hline 6 & 42,00 & 84,00 & 77,25 & 39,00 \\
\hline 7 & 49,00 & 112,00 & 92,91 & 40,00 \\
\hline 8 & 56,00 & 140,00 & 114,01 & 44,00 \\
\hline 9 & 63,00 & 161,00 & 135,11 & 51,00 \\
\hline 10 & 70,00 & 182,00 & 156,21 & 58,00 \\
\hline 11 & 77,00 & 203,00 & 185,47 & 69,00 \\
\hline 12 & 84,00 & 224,00 & 220,34 & 83,00 \\
\hline 13 & 91,00 & 266,00 & 254,50 & 86,00 \\
\hline 14 & 98,00 & 315,00 & 295,67 & 89,00 \\
\hline 15 & 105,00 & 378,00 & 354,33 & 94,00 \\
\hline 16 & 112,00 & 448,00 & 413,00 & 95,00 \\
\hline
\end{tabular}

Sumber : Hasil Analisis Data

Dari hasil analisis dalam perhitungan EDt pada minggu ke-16, EDt menghasilkan perbedaan waktu yang diterima dengan waktu saat pelaporan. Dari perbedaan tersebut dapat dilihat dalam bentuk kurva sebagai berikut.

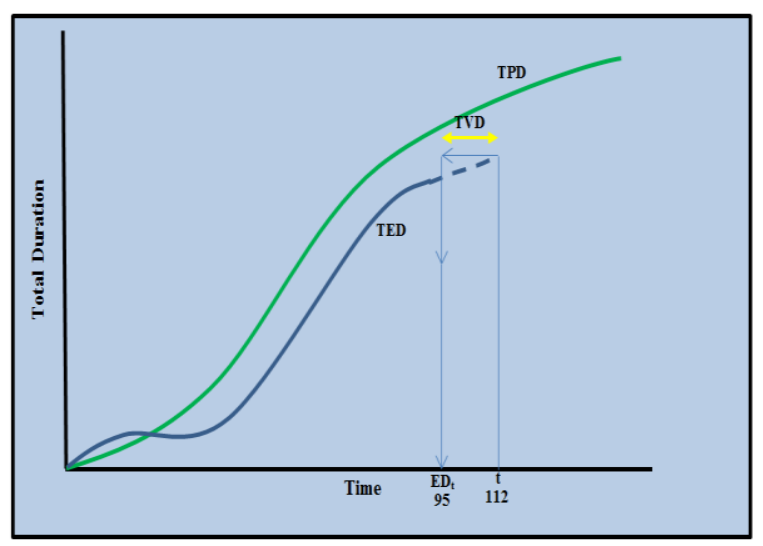

Gambar 2. Kurva earned duration at time

Hasil perhitungan $\mathrm{ED}_{\mathrm{t}}$ dapat kita jelaskan pada pelaporan minggu ke-1 durasi yang diterima saat pelaporan pelaksanaan proyek mengalami peningkatan hingga minggu ke-4 pada saat minggu ke-5 durasi yang diterima saat pelaporan pelaksanaan proyek sama dengan atau proyek dikatakan normal, dan pada saat minggu ke-6 durasi yang diterima saat pelaporan pelaksanaan proyek mengalami penurunan waktu sehingga minggu ke-16 yang menghasilkan durasi waktu pelaksanaan saat pelaporan 95 hari saat ini dapat dikatakan waktu pelaksaan kurang dari waktu rencana 112 hari. selanjutnya dapat kita lakukan indentifikasi duration peformance index dengan perhitungan sebagai berikut.

\section{Duration Performance Index (DPI)}

Pada identifikasi menggunakan perhitungan Duration Performance Index jika menghasilkan kurang dari satu maka penyelesaian proyek dikatakan terlambat, jika Duration Performance Index menghasilkan lebih besar dari satu maka penyelesaian proyek dikatakan lebih cepat, jika Duration Performance Index sama dengan satu maka penyelesaian proyek dikatakan tepat waktu atau berjalannya proyek sesuai dengan rencana.

Perhitungan untuk DPI, adalah :

$\mathrm{DPI}=\mathrm{EDt} / \mathrm{t}$

Minggu Ke-16 Bulan Ke-4

$\mathrm{EDt}=95$ hari

$\mathrm{t} \quad=112$ hari

DPI $=95 / 112$

$=0,8482(<1)$

Rekap perhitungan Duration Performance Index (DPI) pada minggu ke-16 bulan ke-4 kinerja proyek kurang dari satu, dapat dilihat pada Tabel 5. Rekap Perhitungan Duration Performance index sebagai berikut.

Tabel 5. Rekap duration performance index

\begin{tabular}{|c|c|c|c|}
\hline $\begin{array}{c}\text { Minggu } \\
\text { Ke- }\end{array}$ & $\begin{array}{c}\mathbf{t} \\
\text { Hari }\end{array}$ & $\begin{array}{c}\text { EDt } \\
\text { Hari }\end{array}$ & DPI \\
\hline 1 & 7,00 & 11,00 & 1,5714 \\
\hline 2 & 14,00 & 21,00 & 1,5000 \\
\hline 3 & 21,00 & 27,00 & 1,2857 \\
\hline 4 & 28,00 & 33,00 & 1,1786 \\
\hline 5 & 35,00 & 35,00 & 1,0000 \\
\hline 6 & 42,00 & 39,00 & 0,9286 \\
\hline 7 & 49,00 & 40,00 & 0,8163 \\
\hline 8 & 56,00 & 44,00 & 0,7857 \\
\hline 9 & 63,00 & 51,00 & 0,8095 \\
\hline 10 & 70,00 & 58,00 & 0,8286 \\
\hline
\end{tabular}


Tabel 5. Lanjutan

\begin{tabular}{|c|c|c|c|}
\hline $\begin{array}{c}\text { Minggu } \\
\text { Ke- }\end{array}$ & $\begin{array}{c}\text { t } \\
\text { Hari }\end{array}$ & $\begin{array}{c}\text { EDt } \\
\text { Hari }\end{array}$ & DPI \\
\hline 11 & 77,00 & 69,00 & 0,8961 \\
\hline 12 & 84,00 & 83,00 & 0,9881 \\
\hline 13 & 91,00 & 86,00 & 0,9451 \\
\hline 14 & 98,00 & 89,00 & 0,9082 \\
\hline 15 & 105,00 & 94,00 & 0,8952 \\
\hline 16 & 112,00 & 95,00 & 0,8482 \\
\hline
\end{tabular}

Sumber : Hasil Analisis Data

Hasil perhitungan Duration Performance Index (DPI) mulai dari minggu ke-1 hingga minggu ke-4 kinerja waktu proyek lebih dari satu maka pelaksanaan proyek dikatakan lebih cepat dari pada rencana, saat minggu ke-5 kinerja waktu proyek sama dengan satu maka pelaksanaan proyek dikatakan berjalan sesuai rencana, saat minggu ke-6 hingga minggu ke-15 kinerja waktu proyek kurang dari satu maka pelaksanaan proyek dikatakan telambat dari waktu rencana. pada minggu ke-16 bulan ke-4 saat pelaporan di lakukan analisis kinerja waktu yang mendapatkan hasil kinerja waktu proyek kurang dari satu maka dapat di katakan proyek masih mengalami keterlambatan waktu dari jadwal rencana yang dapat mengakibatkan waktu penyelesaian proyek tidak akan selesai pada waktu rencana. Dapat kita perhitungkan besarnya waktu keterlambatan dengan perhitungan Total Duration Variance sebagai berikut.

\section{Total Duration Variance (TDV)}

Perhitungan TDV dapat memperkirakan keterlambatan waktu penyelesaian proyek berikut perhitungan TDV.

Perhitungan untuk TDV, adalah :

$\mathrm{TDV}=\mathrm{t}-\mathrm{EDt}$

Minggu Ke-16 Bulan Ke-4

$$
\begin{aligned}
\mathrm{t} & =112,00 \text { Hari } \\
\mathrm{EDt} & =95,00 \text { Hari } \\
\mathrm{TDV} & =95,00-112,00 \\
& =-17 \text { Hari }
\end{aligned}
$$

Dalam perhitungan Total Duration Variance saat pelaporan minggu ke-16 bulan ke14 proyek Pembangunan Rumah Susun mengalami keterlambatan waktu penyelesaian proyek selama 17 hari. Untuk melengkapi hasil perhitungan dapat di lihat pada tabel 6. Rekap perhitungan Total Duration Variance (TDV) sebagai berikut.

Tabel 6. Rekap total duration variance

\begin{tabular}{|c|c|c|c|}
\hline $\begin{array}{c}\text { Minggu } \\
\text { Ke- }\end{array}$ & $\begin{array}{c}\mathbf{t} \\
\text { Hari }\end{array}$ & $\begin{array}{c}\text { EDt } \\
\text { Hari }\end{array}$ & TDV \\
\hline 1 & 7,00 & 11,00 & 4,00 \\
\hline 2 & 14,00 & 21,00 & 7,00 \\
\hline 3 & 21,00 & 27,00 & 6,00 \\
\hline 4 & 28,00 & 33,00 & 5,00 \\
\hline 5 & 35,00 & 35,00 & 0,00 \\
\hline 6 & 42,00 & 39,00 & $-3,00$ \\
\hline 7 & 49,00 & 40,00 & $-9,00$ \\
\hline 8 & 56,00 & 44,00 & $-12,00$ \\
\hline 9 & 63,00 & 51,00 & $-12,00$ \\
\hline 10 & 70,00 & 58,00 & $-12,00$ \\
\hline 11 & 77,00 & 69,00 & $-8,00$ \\
\hline 12 & 84,00 & 83,00 & $-1,00$ \\
\hline 13 & 91,00 & 86,00 & $-5,00$ \\
\hline 14 & 98,00 & 89,00 & $-9,00$ \\
\hline 15 & 105,00 & 94,00 & $-11,00$ \\
\hline 16 & 112,00 & 95,00 & $-17,00$ \\
\hline
\end{tabular}

Sumber : Hasil Analisis Data

Dari hasil analisis perhitungan TDV pada minggu ke-1 sampai dengan minggu ke-4 waktu pelaksanaan proyek mengalami percepatan, pada minggu ke-5 waktu pelaksanaan proyek normal atau berjalan sesuai dengan rencana, pada saat minggu ke-6 sampai dengan minggu ke-16 waktu pelaksanaan proyek mengalami keterlambatan, dari rekap perhitungan dapat kita lihat pada Gambar 3. Kurva Total Duration Variance sebagai berikut.

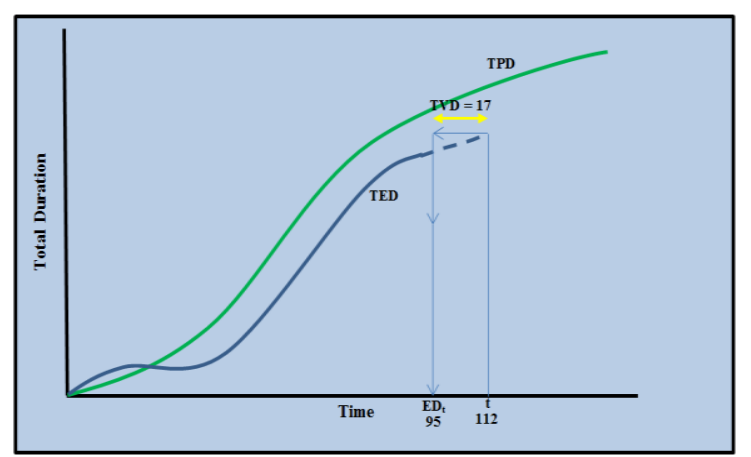

Gambar 3. Kurva total duration variance

Dalam kurva Total Duration Variance $(T D V)$ pada minggu ke-16 bulan ke-4 proyek 
Pembangunan Rumah Susun mengalami keterlambatan waktu selama 17 hari. dapat kita ketahui pada Tabel 6. Rekap perhitungan Total Duration Variance Proyek Pembangunan Rumah Susun mengalami penyimpangan waktu mulai pada saat pelaporan minggu ke-3, di saat minggu ke-11 pelaksanaan proyek mengalami percepatan waktu pelaksanaan dan terjadi peningkatan waktu keterlambatan saat minggu ke-13 hingga kita lakukan analisis kinerja waktu dan total keterlambatan waktu proyek pada minggu ke-16. Analisis waktu pelaksanaan proyek menggunakan metode Earned Duration yang memiliki indikator Total Earned Duration (TED), Total Planned Duration (TPD), dan Total Actual Duration (TAD) dalam hasil akhirnya mendapatkan perkiraan waktu keterlambatan penyelesaian proyek pada minggu ke-1 bulan ke-1 sampai dengan minggu ke-16 nulan ke-4. Untuk melengkapi hasil perhitungan dapat di lihat dalam bentuk tabel. Berikut tabel rekap hasil perhitungan earned duration minggu ke-1 sampai dengan minggu ke-16.

Tabel 7. Rekap hasil perhitungan earned duration minggu ke-1 s/d 16

\begin{tabular}{|c|c|c|c|c|c|c|}
\hline $\begin{array}{c}\text { Minggu } \\
\text { Ke- }\end{array}$ & $\begin{array}{c}\text { t } \\
\text { Hari }\end{array}$ & $\begin{array}{c}\text { TPD } \\
\text { Hari }\end{array}$ & $\begin{array}{c}\text { TED } \\
\text { Hari }\end{array}$ & $\begin{array}{c}\text { EDt } \\
\text { Hari }\end{array}$ & DPI & $\begin{array}{c}\text { TDV } \\
\text { Hari }\end{array}$ \\
\hline 1 & 7,00 & 7,00 & 14,00 & 11,00 & 1,5714 & 4,00 \\
\hline 2 & 14,00 & 14,00 & 28,00 & 21,00 & 1,5000 & 7,00 \\
\hline 3 & 21,00 & 28,00 & 39,20 & 27,00 & 1,2857 & 6,00 \\
\hline 4 & 28,00 & 42,00 & 50,40 & 33,00 & 1,1786 & 5,00 \\
\hline 5 & 35,00 & 63,00 & 61,60 & 35,00 & 1,0000 & 0,00 \\
\hline 6 & 42,00 & 84,00 & 77,25 & 39,00 & 0,9286 & $-3,00$ \\
\hline 7 & 49,00 & 112,00 & 92,91 & 40,00 & 0,8163 & $-9,00$ \\
\hline 8 & 56,00 & 140,00 & 114,01 & 44,00 & 0,7857 & $-12,00$ \\
\hline 9 & 63,00 & 161,00 & 135,11 & 51,00 & 0,8095 & $-12,00$ \\
\hline 10 & 70,00 & 182,00 & 156,21 & 58,00 & 0,8286 & $-12,00$ \\
\hline 11 & 77,00 & 203,00 & 185,47 & 69,00 & 0,8961 & $-8,00$ \\
\hline 12 & 84,00 & 224,00 & 220,34 & 83,00 & 0,9881 & $-1,00$ \\
\hline 13 & 91,00 & 266,00 & 254,50 & 86,00 & 0,9451 & $-5,00$ \\
\hline 14 & 98,00 & 315,00 & 295,67 & 89,00 & 0,9082 & $-9,00$ \\
\hline 15 & 105,00 & 378,00 & 354,33 & 94,00 & 0,8952 & $-11,00$ \\
\hline 16 & 112,00 & 448,00 & 413,00 & 95,00 & 0,8482 & $-17,00$ \\
\hline
\end{tabular}

Sumber : Hasil Perhitungan Earned Duratio

Tabel 7. menyajikan Rekap Perhitungan Earned Duration mulai dari minggu ke-1 bulan ke-1 sampai dengan minggu ke-16 bulan ke-4. Saat pelaporan minggu ke-16 dilakukan analisis menggunakan perhitungan Earned Duration at
Time hanya mencapai 95 hari dari waktu pelaporan 112 hari dan memiliki kinerja waktu pelaksanaan proyek 0,8482 kurang dari satu $(<1)$ dan pelaksanaan proyek akan selesai terlambat selama 17 hari.

\section{KESIMPULAN DAN SARAN}

\section{Kesimpulan}

Kesimpulan dari penelitian ini adalah:

1. Perkiraan waktu pelaporan Proyek Pembangunan Rumah Susun pada minggu ke-16 bulan ke-4 memiliki nilai EDt 95 hari kurang dari 112 hari pada saat waktu pelaporan maka kinerja proyek DPI $0,8482<$ 1, dapat dikatakan kinerja waktu proyek mengalami penurunan dalam pelaksanaan proyek.

2. Hasil analisis keterlambatan waktu pada minggu ke-16 bulan ke-4 pelaksanaan proyek mengalami keterlambatan waktu penyelesaian selama 17 hari kalender.

\section{Saran}

Saran pada penelitian ini adalah :

1. Pihak pelaksana proyek Pembangunan Rumah Susun sebaiknya lebih meningkatkan kinerja waktu. sehingga dapat menghindari keterlambatan waktu penyelesaian proyek.

2. Diperlukan adanya pemantauan kinerja waktu pada tiap periode pelaporan pelaksanaan proyek mengingat faktor-faktor yang dapat mempengaruhi waktu keterlambatan proyek.

\section{DAFTAR PUSTAKA}

Basuki, A. Henny, W. \& Dicky, D. P. (2017). "Model Validasi Penerapan Hasil Pengebangan Earned Value Method Untuk Perkiraan Durasi Akhir Proyek Konstruksi Di Jakarta”. Konferensi Nasional Teknik Sipil 11, Universitas Tarumanagar, 259 264.

Clive, G. (1992). Pengantar Evaluasi Proyek. Gramedia Pustaka Utama, Jakarta.

Imam, S. (1999). Manajemen Proyek. Penerbit Erlangga, Jakarta.

Khamooshi, H. \& Golafshani, H. (2014). "Earned Duration Management, A New Approach To Schedule Performance Management And Measurement". International Journal of Project Management, 32 (6), 1019-1041. 
Olivia, P. \& Puspasari, V. H. (2019). "Analisis Pecepatan Waktu Proyek Menggunakan Metode Crasshing (Studi Kasus: Peningkatan Jalan Pelantaran-PerenggeanTumbang Sangai)". Jurnal Teknika, Vol. III, No. 1, Hal. 42.

Pratama, F. Waluyo, R. \& Puspasari, V. H. (2019). "Analisis Kinerja Proyek Peningkatan Jalan Pelantaran-ParenggeanTumbang Sangai Dengan Metode Eaned Value". Jurnal Teknika, Vol. III, No. 1, Hal. 2.

Rian. (2014)."Evaluasi Pengendalian Waktu dan Biaya Menggunankan Metode PERT Pada Pelaksanaan Pekerjaan Jembatan Desa Pengkol Kecamatan Karanggede Kabupaten Boyolali". Teknik Sipil Universitas Muhammadiyah Surakarta. 2014, 1 - 17.

Vendie, A. (2016). "Analisi Pengendalian Waktu Dengan Earned Value Pada Proyek Pembangunan Hotel Fave Kota Baru Yogyakarta". Jurnal Teknisia, Vol. XXI, 218 228. 